\title{
Nachrichten der Deutschen Gesellschaft für
}

\section{Nuklearmedizin}

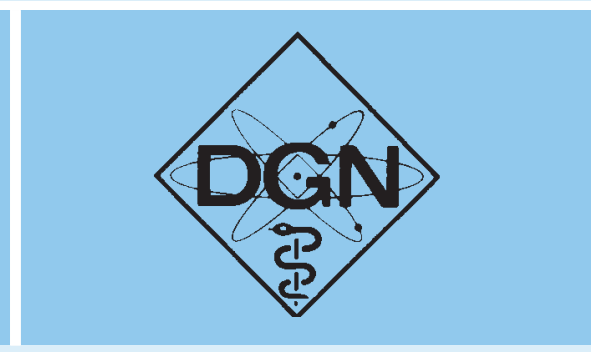

\section{Personalia}

Im Januar 2021 ist Herr Priv.-Doz. Dr. med. Wolfgang Peter Fendler ( $\triangleright$ Abb. 1) zum außerplanmäßigen Professor der Medizinischen Fakultät der Universität DuisburgEssen ernannt worden.

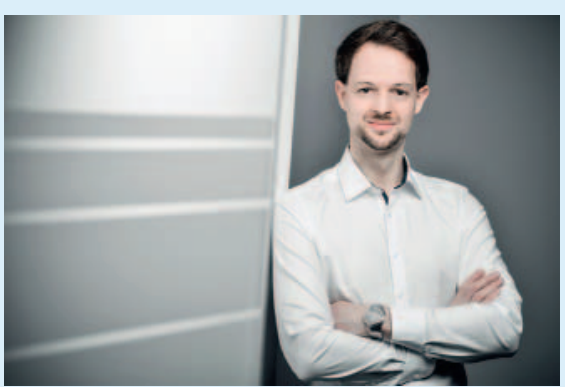

- Abb. 1 Prof. Dr. med. Wolfgang Peter Fendler. Quelle: Fendler: privat.
Nach seinem Medizinstudium in Erlangen und München war er ab 2011 an der Klinik und Poliklinik für Nuklearmedizin der Ludwig-Maximilians-Universität München tätig, wo er im Jahr 2012 auch promovierte und im Jahr 2017 seine Anerkennung zum Facharzt für Nuklearmedizin erlangte. 2017 folgte dort dann seine Habilitation zum Thema „Molekulare Bildgebung zur Risikostratifizierung in der Onkologie“.

Im Anschluss arbeitete Herr Professor Fendler als Visiting Assistant Professor im Department of Molecular and Medical Pharmacology an der UC Los Angeles School of Medicine (USA) und nahm nach seiner Rückkehr nach Deutschland in Jahr 2018 eine Beschäftigung als Leitender Oberarzt an der Klinik für
Nuklearmedizin des Universitätsklinikums Essen auf, wo er auch heute noch tätig ist.

Die DGN gratuliert Herrn Professor Fendler sehr herzlich.

VERANTWORTLICH FÜR DEN INHALT

\section{Deutsche Gesellschaft für} Nuklearmedizin e. V. (DGN)

Prof. Dr. Bernd Joachim Krause

(Präsident)

Nikolaistr. 29

37073 Göttingen

E-Mail: office@nuklearmedizin.de Schriftführer:

Prof. Dr. Peter Bartenstein

E-Mail: office@nuklearmedizin.de 